\author{
Maria Flytzani-Stephanopoulos \\ Adel F. Sarofim \\ Yanping Zhang
}

Quarterly Technical Progress Report No. 4 July - September 1992

Prepared for:

U.S. Department of Energy

Pittsburgh Energy Technology Center

Pittsburgh, Pennsylvania

Technical Project Officer - Dr. K. Das (DOE/METC)

Grant No. DE-FG22-91PC91923

by

Massachusetts Institute of Technology

Department of Chemical Engineering

Cambridge, Massachusetts

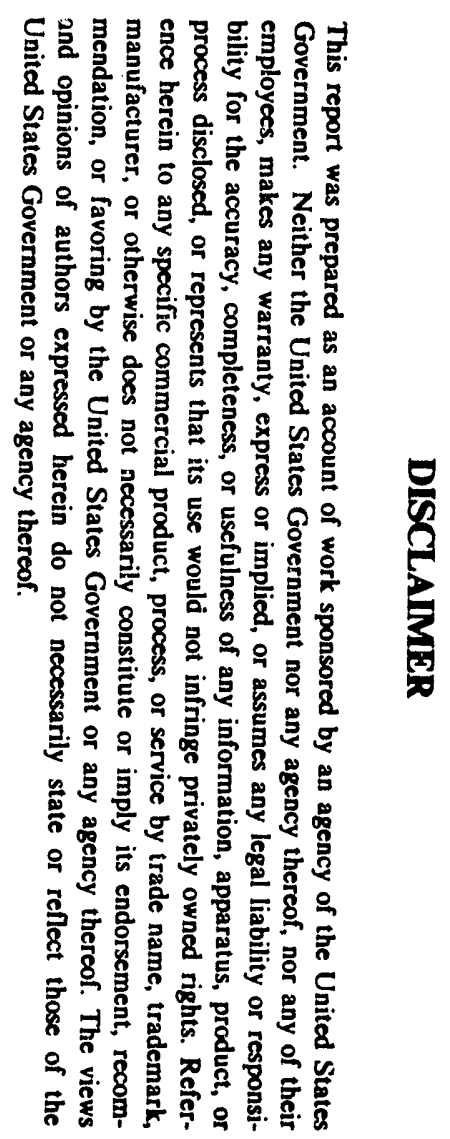

"US/DOE Patent Clearance is not required prior to the publication of this document." 


\title{
Project Title: DIRECT CATALYTIC DECOMPOSITION OF NITRIC OXIDE
}

\begin{abstract}
This project investigates a suitable catalyst system for the direct NO decomposition in post-combustion $\mathrm{NO}_{\mathbf{X}}$ control. The process does not use a reductant, such as the ammonia used in the case of Selective Catalytic Reduction (SCR) of NOx to nitrogen. Therefore, it is a greatly simplified process basically involving passing the flue gas through a catalytic converter.

Catalysts are prepared by incorporating metal cations into zeolite supports according to ion exchange procedures widely used in preparation of metal/zeolite catalysts. The catalysts of primary interest include copper, palladium, silver, and nickel exchanged zeolites. Particular emphasis is given in this work on promoted Cu-exchanged zeolites, especially the catalyst system $\mathrm{Mg} / \mathrm{Cu}-\mathrm{ZSM}-5$ and a few others, which are promising for $\mathrm{NO}$ conversion to nitrogen at typical flue gas $\mathrm{O}_{2}$ and $\mathrm{NO}$ levels and over the temperature range of $723-873 \mathrm{~K}$. Effects of zeolite modification, copper exchange level and catalyst preparation conditions on the catalyst activity are studied in a packed-bed microreactor. Temperature-programmed desorption (TPD) and reduction (TPR) experiments will be carried out in a thermogravimetric analyzer and a single-particle electrodynamic balance (EDB). Kinetic studies of $\mathrm{NO}$ and $\mathrm{O}_{2}$ interaction with catalysts over a wide temperature range as well as catalyst structural investigations are planned.
\end{abstract}

\section{PROGRESS SUMMARY}

\section{Catalyst Synthesis and Characterization}


During this quarter, 15 catalyst samples, listed in Table 1, were prepared by exchanging metal cations, $\mathrm{Cu}^{2+} / \mathrm{Mg}^{2+} / \mathrm{Zn}^{2+}$, into the $\mathrm{Na}-\mathrm{ZSM}-5$ zeolite substrates. The exchange procedures are triefly described below. For the catalysts \#7-\#9, the Na-ZSM-5 was ion-exchanged in a solution of copper (II) acetate with concentration of $0.5 \mathrm{mmol} / \mathrm{dm}^{3}$ and with ammonia addition (at a ratio of $\mathrm{NH}_{4}+/ \mathrm{Cu}^{2+}=0.5$ ) at $50^{\circ} \mathrm{C}$ overnight, and separated from the solution by filtration. The obtained wet cake was again ion-exchanged in a new copper(II) acetate and ammonia solution. After 3 time repeats of the ion exchange treatment, the sample was washed in deionized water and dried at $110{ }^{\circ} \mathrm{C}$ overnight. For the remaining of $\mathrm{Cu}$ exchanged zeolite catalysts, the preparation procedure was the same as that for catalysts \#7-\#9, except no ammonia was added in the solution. For $\mathrm{Mg} / \mathrm{Cu}$-exchanged zeolites, the $\mathrm{Na} / \mathrm{ZSM}-5$ zeolites were ion-exchanged with $\mathrm{Mg}^{2+}$ in a $\mathrm{Mg}\left(\mathrm{i} \mathrm{O}_{3}\right)_{2}$ solution with concentration of $0.3-0.8 \mathrm{mmol} / \mathrm{dm}^{3}$ at $90^{\circ} \mathrm{C}$ for two hours first. The $\mathrm{Mg}$ exchange level was about $50 \%$ in the obtained zeolites. After the $\mathrm{Mg}^{2+}$ exchanged zeolites were seperated from the solution by filtration, the samples were ion-exchanged overnight with $\mathrm{Mg}^{2+}$ and $\mathrm{Cu}^{2+}$ cations simultaneously in $\mathrm{Mg}\left(\mathrm{NO}_{3}\right)_{2}$ and $\mathrm{Cu}\left(\mathrm{OOCCH}_{3}\right)_{2}$ solution, in which $\mathrm{Mg}\left(\mathrm{NO}_{3}\right)_{2}$ and $\mathrm{Cu}\left(\mathrm{OOCCH}_{3}\right)_{2}$ concentrations were about $0.3-0.8 \mathrm{mmol} / \mathrm{dm}^{3}$. Since $\mathrm{Cu}$ cations are easier to exchange $\mathrm{Na}+$ in Na-ZSM-5 than $\mathrm{Mg}$ cations(1), it is hard to get high Mg loading in ZSM-5 according to the above technique. We will continue to work on this by modifying our exchange procedure. All samples were characterized by Plasma Emission Spectrometry (ICP) (Perkin-Elmer Plasma 40) to measure contents of metal cations exchanged into the zeolites after dissolving samples in an $\mathrm{HNO}_{3}$ solution and by checking the aqueous metal cation solutions before and after the exchange step. The $\mathrm{Cu}^{2+}$ exchange levels range from $73 \%$ to $150 \%$ in the $\mathrm{Cu}^{2+-}$ exchanged zeolites, 
while $\mathrm{Mg}^{2+}$ exchange levels of $0.6 \%$ to $11 \%$ and $\mathrm{Cu}^{2+}$ levels of $50 \%$ to $72 \%$ were measured in $\mathrm{Mg}^{2+} / \mathrm{Cu}^{2+}$-exchanged zeolites. The high $\mathrm{Mg}$ loading of catalyst \#16 resulted from impregnation using a concentrated $\left(85 \mathrm{mmol} / \mathrm{dm}^{3}\right.$ ) $\mathrm{Mg}\left(\mathrm{NO}_{3}\right)_{2}$ solution. The $\mathrm{Zn}^{2+}$ and $\mathrm{Cu}^{2+}$ exchange levels are $76.6 \%$ and $44.5 \%$, respectively, in the $\mathrm{Zn}^{2+}$ and $\mathrm{Cu}^{2+}$ co-cation exchanged zeolite. For catalysts \#20 and \#21, different parent zeolites were used, namely $881027 \mathrm{~b}$ ZSM-5 and high Si/Al ratio ZSM-5 supplied, respectively, by Dr. Patric Voogd of Delft University of Technology, the Netherlands and Davison Co., with respective $\mathrm{Si} / \mathrm{Al}$ ratio of 90 and 320 . The $\mathrm{ICP}$ was recalibrated after an error had been found. This error affects the previously reported measurements. A corrected Table 2 from the 3rd Quarterly Report(2) is provided in the appendix.

The new catalysts are used to test the effects of copper exchange level, promoter cations and acidity ( $\mathrm{Si} / \mathrm{Al}$ ratio) of the parent zeolites on the catalytic activity.

\section{Experimental}

Continued testing of the catalysts prepared during the last and this quarter was performed to study the effects of $\mathrm{Cu}^{2+}$ exchange level and the promoting effect of $\mathrm{Mg}^{2+}$ on the catalytic activity of ion exchanged zeolites. Comparisons of NOx analyzer and GC measurements were made to check their agreement. The experimental conditions used this quarter are the following: reaction temperatures $350^{-} 600^{\circ} \mathrm{C}$, contact time $1-4 \mathrm{~g} \mathrm{~s} / \mathrm{cc}(\mathrm{STP})$, NO concentration $0.2 \%$ $4 \%$, and $\mathrm{O}_{2}$ concentration $0 \%-0.61 \%$. The heat pretreatment of catalysts for catalytic activity measurements consisted of heating the catalyst in $\mathrm{He}$ at $500^{\circ} \mathrm{C}$ for two hours. Long-term tests of catalyst activity were performed with catalyst \#4. The decomposition of $\mathrm{NO}_{2}$ was also examined this quarter over catalyst \#4. 


\section{$\underline{\text { Results and discussion }}$}

In previous work, we mainly used a NOx chemiluminescence analyzer to monitor concentrations of NO and NOx down stream of the reactor. The difference between the $\mathrm{NO}$ and $\mathrm{NOx}$ measurement is due to $\mathrm{NO}_{2}$ formation. This quarter, a gas chromatography with a thermal conductivity detector was also used to check $\mathrm{O}_{2}$ and $\mathrm{N}_{2}$ formation. A molecular sieve $13 \mathrm{X}$ column( 1/4" I.D. $\times 6 \mathrm{ft}$ long) was used in the GC. The $\mathrm{NO}$ conversion into $\mathrm{O}_{2}$ and $\mathrm{N}_{2}$ was determined by $\left(\mathrm{O}_{2}\right.$ or $\mathrm{N}_{2}$ concentration in exit gas)/ (1/2* NO concentration in inlet gas stream).

GC measurements and NOx analyzer measurements were compared for measurement consistency. Fig.1 shows that conversions calculated based on $\mathrm{NO}, \mathrm{NOx}$ measurements from the NOx analyzer, and $\mathrm{O}_{2}, \mathrm{~N}_{2}$ measurements from the GC over catalyst \#4 at a contact time of $4 \mathrm{~g} \mathrm{~s} / \mathrm{cc}$ and $2 \%$ NO in the gas were in good agreement. When the contact time was decreased to $1 \mathrm{~g} \mathrm{~s} / \mathrm{cc}$, and NO concentration to $0.2 \%$, NO conversion to $\mathrm{N}_{2}$ computed from the GC and NOx analyzer measurements were almost the same over whole temperature range. These results are shown in Fig. 2.

However, variations between $\mathrm{NO}$ conversion and $\mathrm{O}_{2}$ and $\mathrm{N}_{2}$ formation are typically reported in the literature, when using gas chromatography data alone. The reason for this is that $\mathrm{NO}_{2}$ is homogeneously produced in the cool parts of the reactor discharge system by the reaction of unconverted NO with produced $\mathrm{O}_{2}(3,4)$. When $\mathrm{NO}$ conversion to $\mathrm{N}_{2}$ is high, the concentration of the unreacted $\mathrm{NO}$ in the exit stream is low. Therefore, $\mathrm{NO}_{2}$ formation decreases as $\mathrm{NO}$ conversion to $\mathrm{N}_{2}$ increases. Also low levels of $\mathrm{NO}_{2}$ were measured when the initial concentration of NO was low( e.g. Fig.2).

The effect of contact time on the NO conversion to $\mathrm{N}_{2}$ and $\mathrm{O}_{2}$ over catalyst \#4 was examined by the GC with a gas containing $4 \% \mathrm{NO}$ at a 
temperature of $450^{\circ} \mathrm{C}$. As we reported before (2), NO conversion measured by the NOx chemiluminescence analyzer increased with the contact time. Our GC measurements presently show that the $\mathrm{O}_{2}$ and $\mathrm{N}_{2}$ products increase with the contact time, as can be seen in Fig. 3. However, there exists a difference between $\mathrm{NO}$ conversion to $\mathrm{N}_{2}$ and between $\mathrm{N}_{2}$ and $\mathrm{O}_{2}$ produced, simlilar to what has been reported in the literature $(3,4)$ in the temperature studies of $\mathrm{Cu} / \mathrm{ZSM}-5$ catalysts. At the temperature of $450^{\circ} \mathrm{C}$, studied here, no $\mathrm{N}_{2} \mathrm{O}$ is formed. The difference, then, is attributed to $\mathrm{NO}_{2}$ production. This is almost constant over the studied range of contact time. At low contact time, the concentration of unreacted NO is high, whereas the residence time of NO and $\mathrm{O}_{2}$ in the reaction system is short. At high contact time, the NO concentration in the exit gas stream is low, but the residence time of gas reactants is long. Combined, the effects of the $\mathrm{NO}+\mathrm{O}_{2}$ reaction rate and the product gas residence time make the $\mathrm{NO}_{2}$ formation approximately the same.

$\mathrm{Mg}^{2+}$ cations were found to promote the catalytic activity of $\mathrm{Cu}^{2+}$ exchanged ZSM-5 when $\mathrm{O}_{2}$ was present in the feed stream. Fig.4 shows NO conversions to $\mathrm{N}_{2}$ over catalyst \#4 at a contact time of $4 \mathrm{~g} \mathrm{~s} / \mathrm{cc}$ without $\mathrm{O}_{2}$ and with $0.61 \% \mathrm{O}_{2}$ in the inlet stream. It is clearly seen that the oxygen presence in the feed gas stream did not reduce the catalytic activity of this $\mathrm{Mg}^{2+} / \mathrm{Cu}^{2+}$ cocation exchanged sample. However, the catalytic activity of $\mathrm{Cu}^{2+}$ exchanged ZSM-5 decreases when $\mathrm{O}_{2}$ is present in the reactor feed gas. Figure 5 shows this for catalyst \#6 for NO decomposition with or without $\mathrm{O}_{2}$ in the $\mathrm{He}+\mathrm{NO}$ stream.

The catalytic activity of $\mathrm{Cu}^{2+} / \mathrm{Mg}^{2+}$ ion exchanged zeolites did not deteriorate over long term run. Figure 6 is a test result over six days of NO decomposition into $\mathrm{N}_{2}$ over catalyst \#4 at $4 \% \mathrm{NO}$ concentration and $450^{\circ} \mathrm{C}$.

Our GC measurements have confirmed that the inlet NO concentration doesn't affect the NO conversion much when the inlet NO consentration is 
above $0.5 \%$ (2). The results of NO conversion into $\mathrm{N}_{2}$ over catalyst \#6 at $2 \%$ and $4 \%$ of NO concentrations are shown in Figure 7 . The NO conversions are same over temperature ranging from 350 to $600^{\circ} \mathrm{C}$.

$\mathrm{Mg}^{2+} / \mathrm{Cu}^{2+}$ co-cation exchanged ZSM-5 is active for $\mathrm{NO}_{2}$ decomposition to $\mathrm{NO}$ and $\mathrm{O}_{2}$. A preliminary run of direct decomposition of $\mathrm{NO}_{2}$ over catalyst \#4 was performed, and results are shown in the Fig. 8. The $\mathrm{NO}_{2}$ conversion was higher than $75 \%$ over temperature range of 350 to $600^{\circ} \mathrm{C}$.

\section{Plans for Next Quarter}

Testing of $\mathrm{Cu}^{2+} / \mathrm{ZSM}-5$ catalysts promoted with cations, such as $\mathrm{Mg}^{2+}$, $\mathrm{Zn}^{2+}, \mathrm{Ag}^{2+}$, and $\mathrm{Pt}^{2+}$ will be conducted to examine what role these cations play in the NO decomposition in the zeolite catalysts. The effect of acidity of parent ZSM-5 on the catalytic activity will be tested at various conditions. Titration of the acid sites in the ion exchanged ZSM- 5 is planned to determine whether the number of copper and other cations correlate with the available acid sites in the zeolite sample.

\section{References}

1. P. Chu and F. G. Dwyer, Intrazeolite Chemistry edited by G. D. Stucky and F. G. Dwyer, pp. 59-78 (1983).

2. M. Flytzani-Stephanopoulos, A.F. Sarofim, Y. P. Zhang, and E. Liang, 3rd Quarterly Report/ Grant NO. DE-FG22-91PC91923. 
3. M. Iwamoto, H. Yahiro, Y. Mine, and S. Kagawa, Chemistry Letters, pp. 213-216(1989).

4. Y. Li and W. K. Hall, J. Phys. Chem., 94(6), pp.6145-6148 (1990). 
Table 1. Cation Exchanged Zeolites $\#$

$\begin{array}{lllll}\begin{array}{l}\text { Catalyst } \\ \text { Number }\end{array} & \text { Si/Al } & \begin{array}{l}\text { Cu Exchanged } \\ \text { level (\%) }\end{array} & \begin{array}{l}\text { Mg Exchanged } \\ \text { level (\%) }\end{array} & \text { note } \\ 7 & 21.5 & 113 & & \mathrm{a} \\ 8 & 21.5 & 108 & & \\ 9 & 21.5 & 99 & 5 & \mathrm{a} \\ 10 & 21.5 & 50 & 5.2 & \\ 11 & 21.5 & 53 & 11 & \mathrm{~b} \\ 12 & 21.5 & 150 & & \mathrm{c} \\ 13 & 21.5 & 72 & 0.6 & \mathrm{a} \\ 14 & 21.5 & 73 & 490 & \\ 15 & 21.5 & 67.2 & \mathrm{Zn}=76.6 & \\ 16 & 21.5 & 14 & & \\ 17 & 21.5 & 145 & & \\ 18 & 21.5 & 44.5 & \mathrm{~N} / \mathrm{A} & \\ 19 & 21.5 & 82 & & \\ 20 & 90 & 64 & & \\ 21 & 320 & & & \end{array}$

\# Zeolites: Na-ZSM-5( low ratio: Si/Al=21.5, and high ratio:

$\mathrm{Si} / \mathrm{Al}=320$ ) supplied by Davison; Catalyst $\# 20$ with $\mathrm{Si} / \mathrm{Al}=90$ was prepared at Delft University of Technology, The Netherlands.
a. CuO particle formation indicated by color change.
b. Mg was put into zeolite by impregnation method.
c. $\mathrm{Zn}$ cation exchanged instead of $\mathrm{Mg}$. 


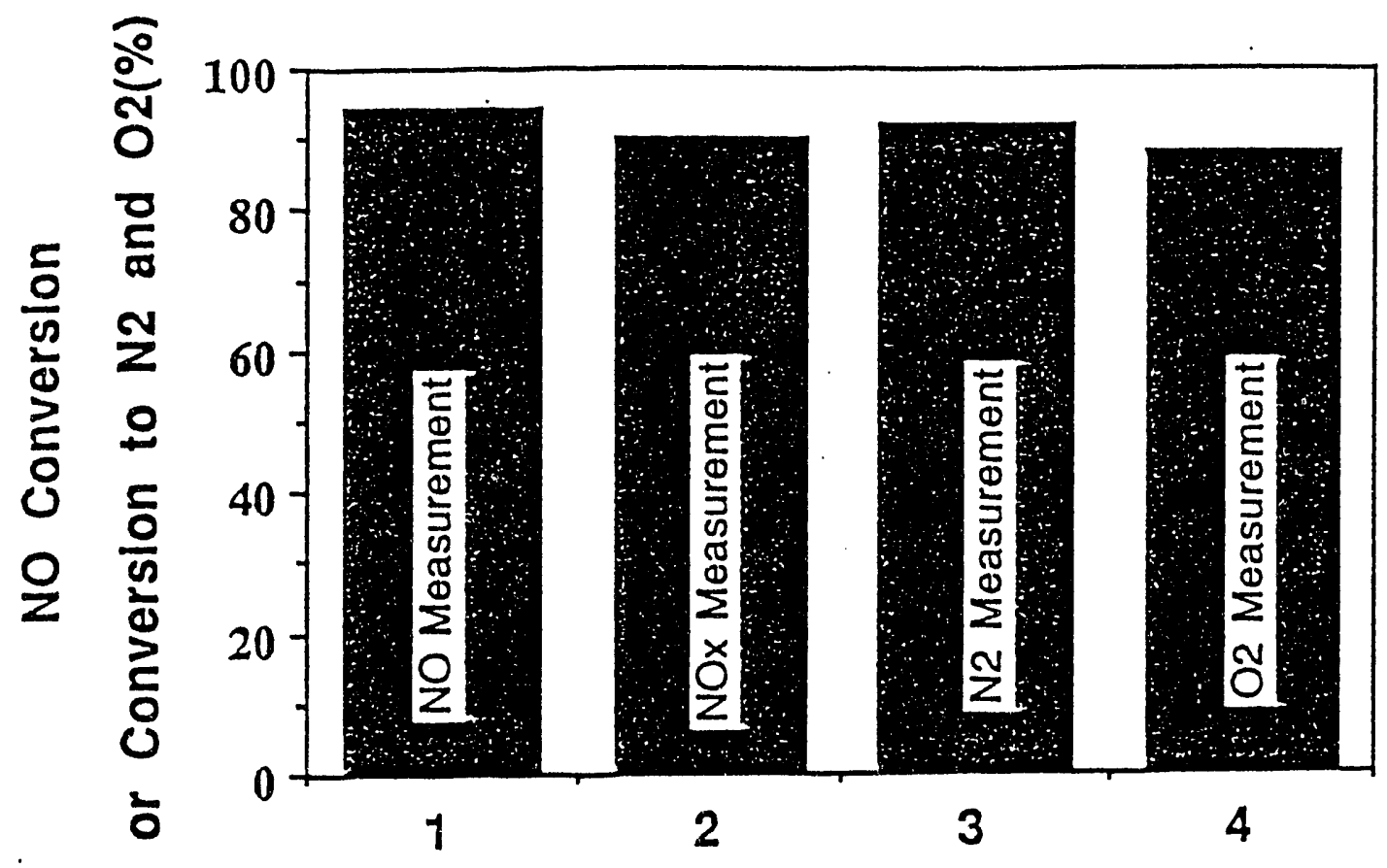

Fig.1 Comparison of NOx analyzer and GC measurement for NO decomposition over catalyst\#4[Mg(11\%)/Cu(119\%) $-Z S M-5]$ at $450^{\circ} \mathrm{C}$ reaction temperature, $2 \% \mathrm{NO}-\mathrm{He}$ and contact time, $W / F=4 \mathrm{~g} s / \mathrm{cc}$.

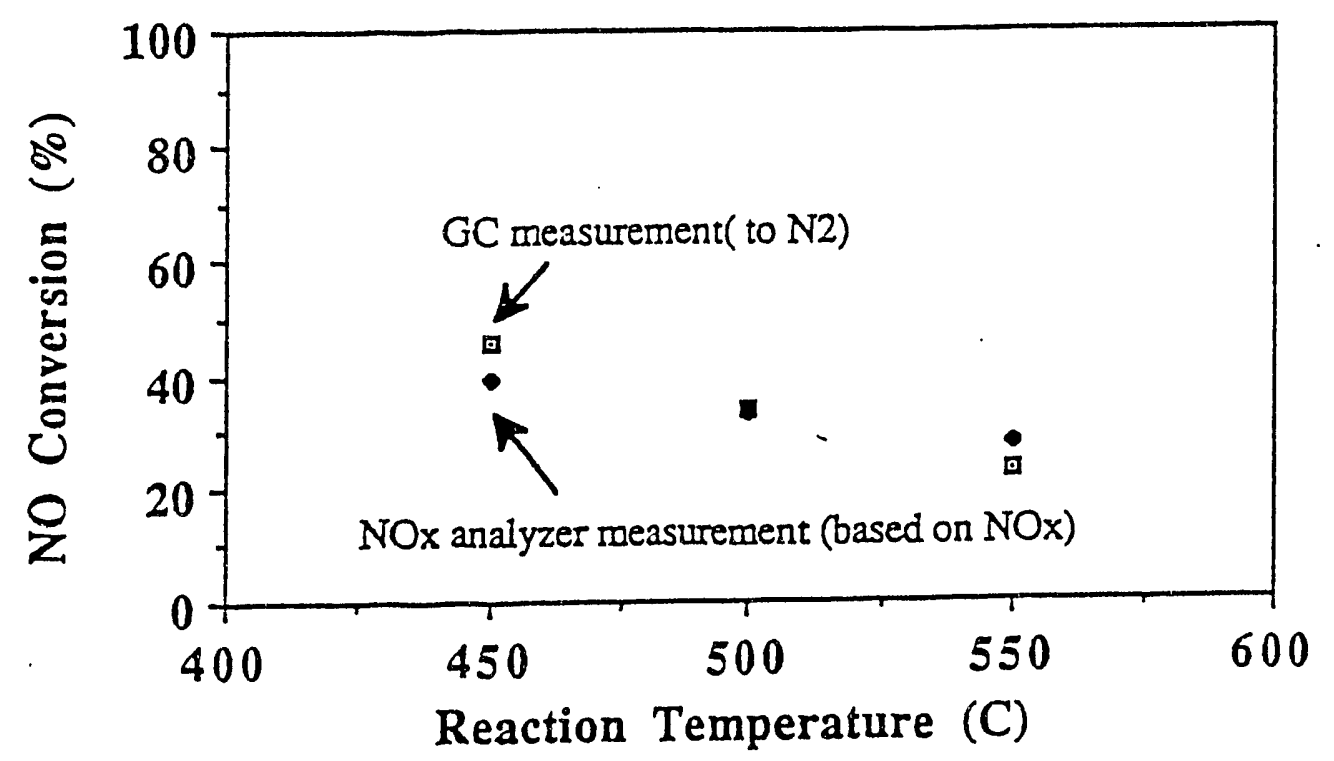

Fig.2 NO decomposition over catalyst \#4 at $0.2 \%$ NO-He, and $W / F=1 \mathrm{~g} / \mathrm{cc}$. 


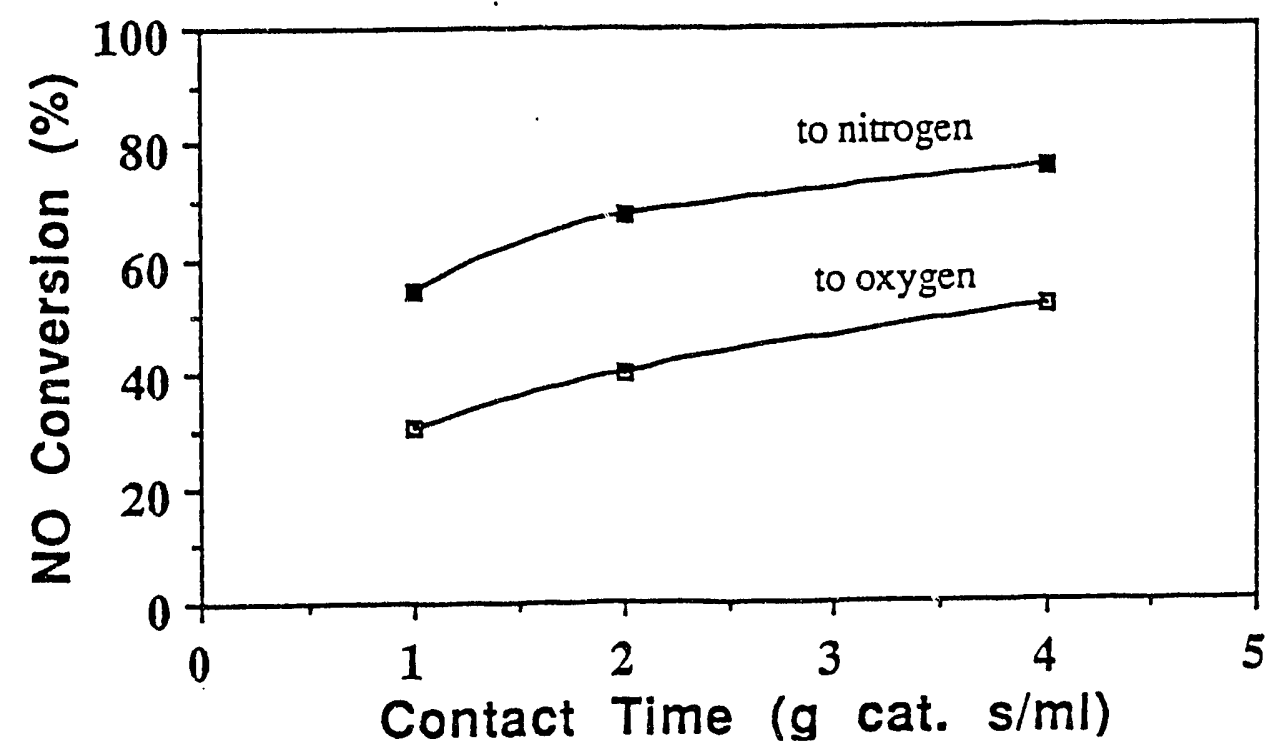

Fig.3 Effect of contact time on NO conversion over catalyst $\# 4$ at $450^{\circ} \mathrm{C}$ and $4 \% \mathrm{NO}-\mathrm{He}$.

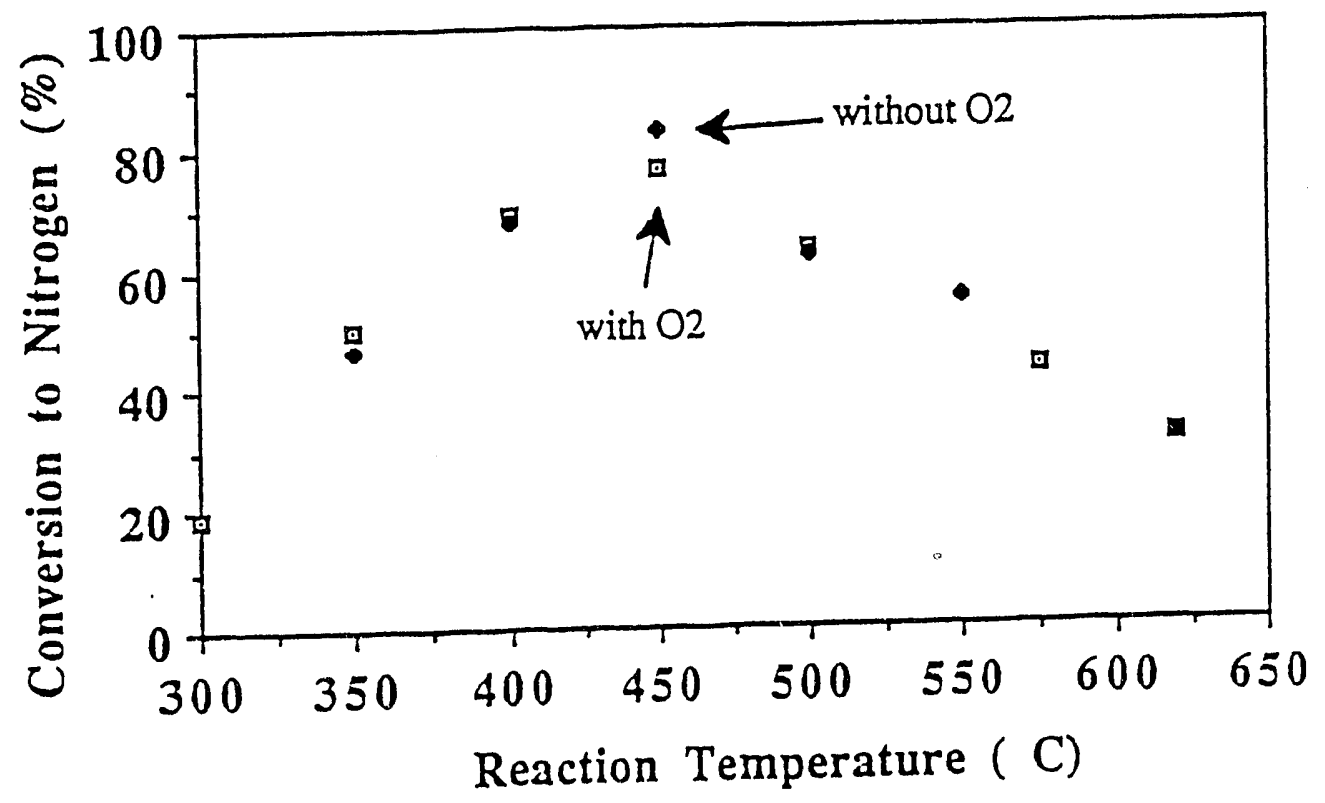

Fig.4 Effect of $\mathrm{O}_{2}$ present in feed gas on NO decomposition to $\mathrm{N}_{2}$ over catalyst \#4 with $2 \%$ of $\mathrm{NO}$ and a contact time of $4 \mathrm{~g} \mathrm{~s} / \mathrm{cc}\left(\diamond\right.$ - without $\mathrm{O}_{2}$, v -with $0.61 \% \mathrm{O}_{2}$ ). 


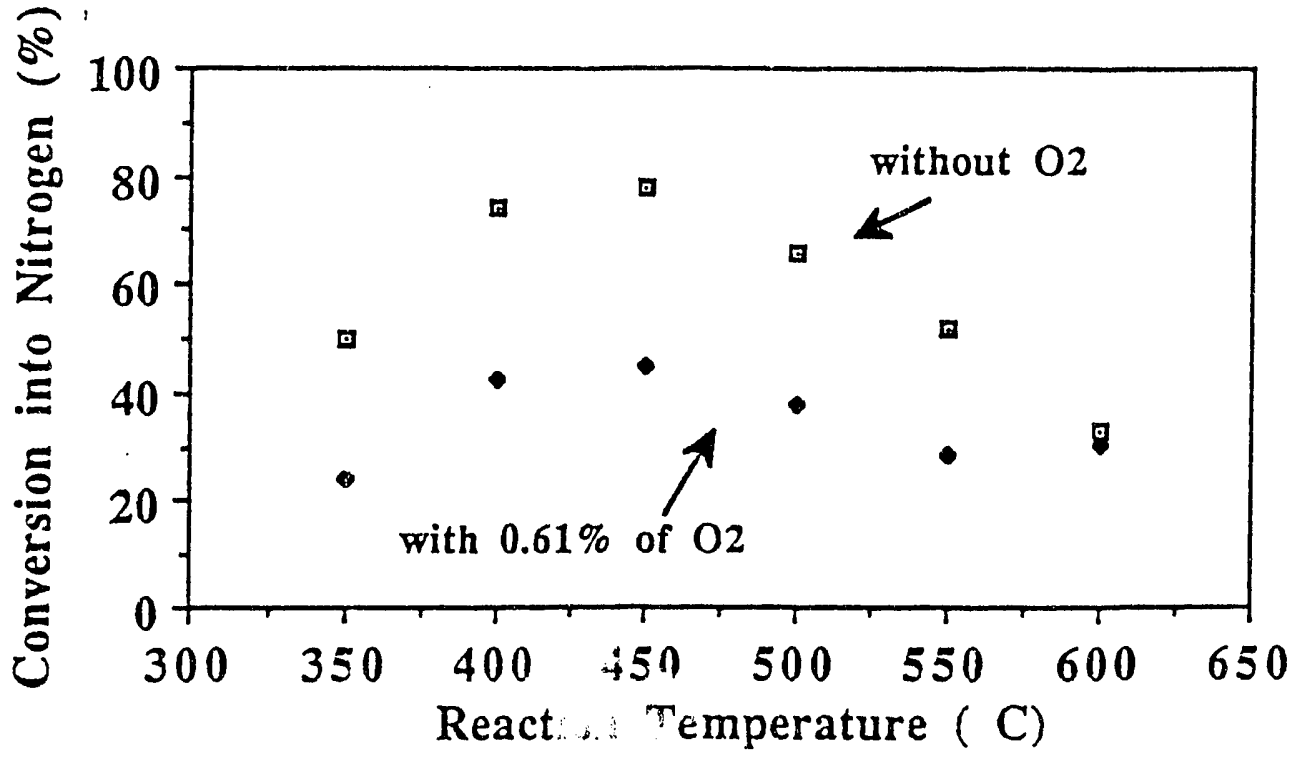

Fig.5 Effect of $\mathrm{O}_{2}$ present in feed gas stream on NO conversion to $\mathrm{N}_{2}$ over catalyst \#6[ $\left.\mathrm{Cu}(108) / Z S M-5\right]$ with $2 \%$ $\mathrm{NO}-\mathrm{He}$ and a contact time of $4 \mathrm{~g} \mathrm{~s} / \mathrm{cc}\left(\mathrm{O}\right.$ - without $\mathrm{O}_{2}$, with $0.61 \% \mathrm{O}_{2}$ ).

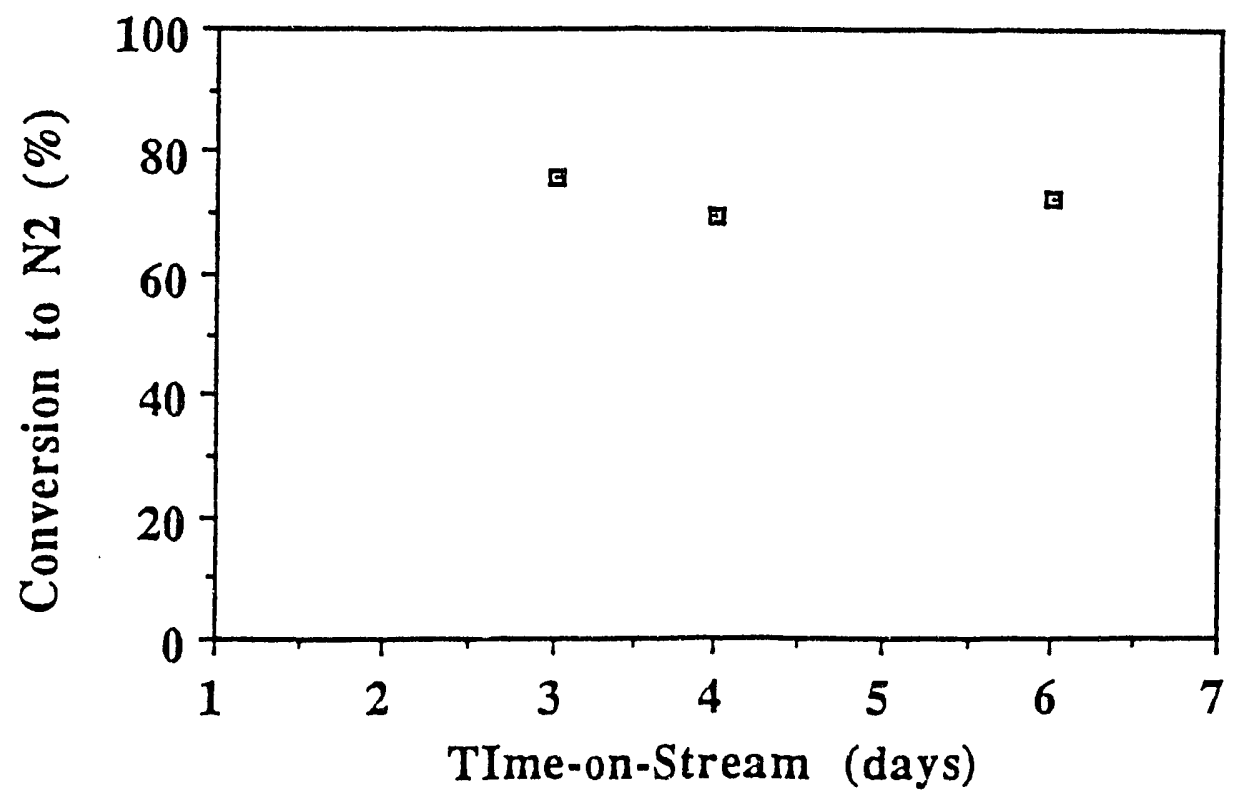

Fig.6 Long-term activity of catalyst \#4 as a function of reaction time at $450^{\circ} \mathrm{C}$ temperature, $4 \% \mathrm{NO}-\mathrm{He}$ and a contact time of $4 \mathrm{~g} \mathrm{~s} / \mathrm{cc}$. 


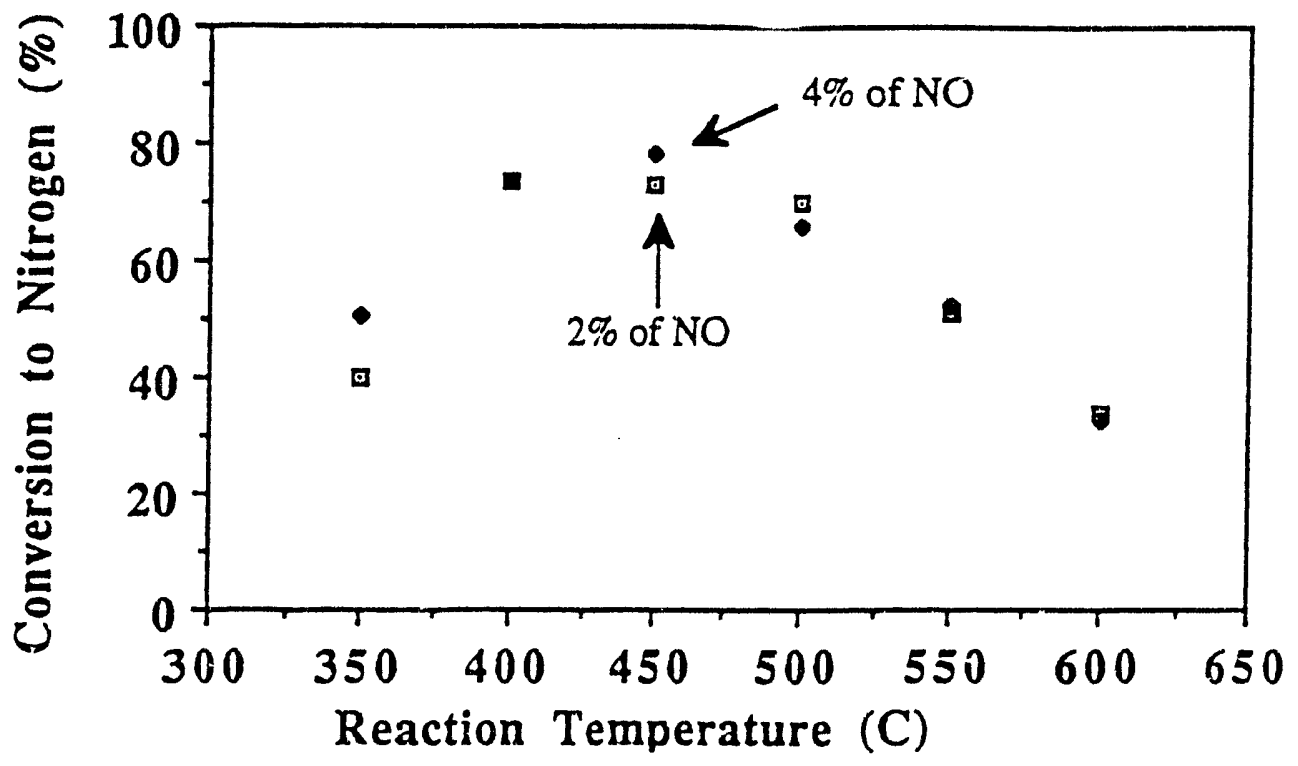

Fig.7 Activity of catalyst \#6 at a contact time of $4 \mathrm{~g} \mathrm{~s} / \mathrm{cc}$ and different NO feed concentrations.

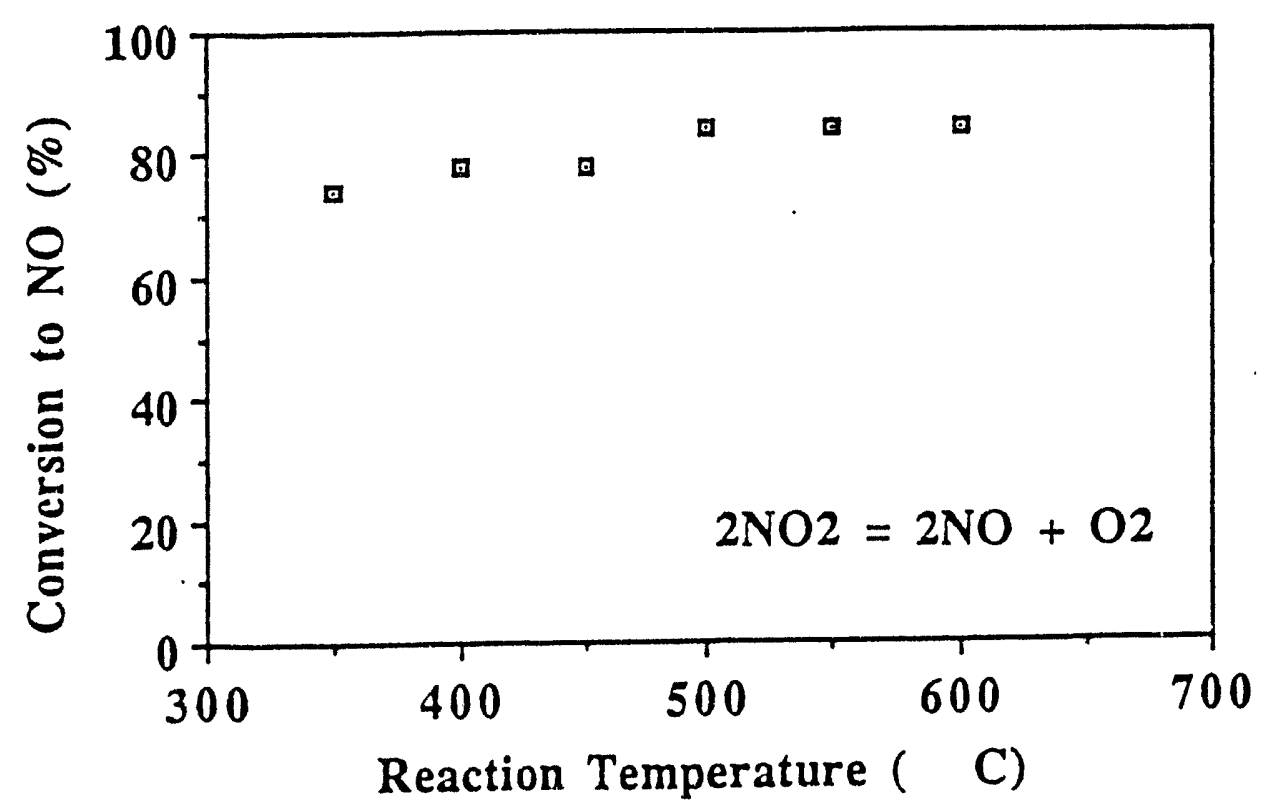

Fig.8 $\mathrm{NO}_{2}$ decomposition over catalyst \#4 as a function of reaction temperature at $467 \mathrm{ppm}$ of $\mathrm{NO}_{2}-\mathrm{He}$ and a contect time of $2 \mathrm{~g} \mathrm{~s} / \mathrm{cc}$. 


\section{Appendix}

Table 2. Sur mary of Cation Exchange Levels of Catalysts

\begin{tabular}{|c|c|c|c|c|c|c|}
\hline \multirow{2}{*}{$\begin{array}{l}\text { Catalyst } \\
\text { Number }\end{array}$} & \multicolumn{2}{|c|}{$\begin{array}{c}\mathrm{Cu}^{2+} \text { in Solution }{ }^{\mathrm{a}} \\
(\mathrm{ppm})\end{array}$} & \multirow{2}{*}{$\begin{array}{c}\mathrm{Mg}^{2+} \text { in Solution } \\
(\mathrm{ppm}) \\
\underline{\mathrm{ICP}}\end{array}$} & \multirow{2}{*}{$\begin{array}{l}\text { Catalyst } \\
\text { Weight } \\
\text { (g) }\end{array}$} & \multicolumn{2}{|c|}{$\begin{array}{c}\text { Exchange Level } \\
(\%)\end{array}$} \\
\hline & $\mathrm{ICP}$ & $\mathrm{AA}$ & & & $\mathrm{Cu}^{2+}$ & $\underline{\mathrm{Mg}^{2}+}$ \\
\hline 1 & 10.1 & 10.8 & & 0.10366 & $96.7(103)^{d}$ & \\
\hline $2^{b, c}$ & 10.8 & 11.43 & & 0.10185 & $\mathrm{~N} / \mathrm{A}$ & \\
\hline & 11.5 & 12.2 & & 0.10644 & $\mathrm{~N} / \mathrm{A}$ & \\
\hline 3 & 11.6 & 12.3 & & 0.10496 & $101(107)$ & \\
\hline 4 & 10.7 & 11.4 & 0.2 & 0.10459 & $112(119)$ & 11 \\
\hline 5 & 9.4 & 10.0 & 0.1 & 0.10500 & $88(93)$ & 5.6 \\
\hline 6 & 9.0 & 9.5 & 0.1 & 0.09892 & $89(93.9)$ & 5.9 \\
\hline
\end{tabular}
a. $203 \mathrm{ml}$ of $1 \% \mathrm{HNO}_{3}$ solution
b. no Si/Al data available at this point
c. data in second line for catalyst $\# 2$ calcinated in air at $500^{\circ} \mathrm{C}$ for 2 hours
d. data in parenthesis calculated from AA measurements 

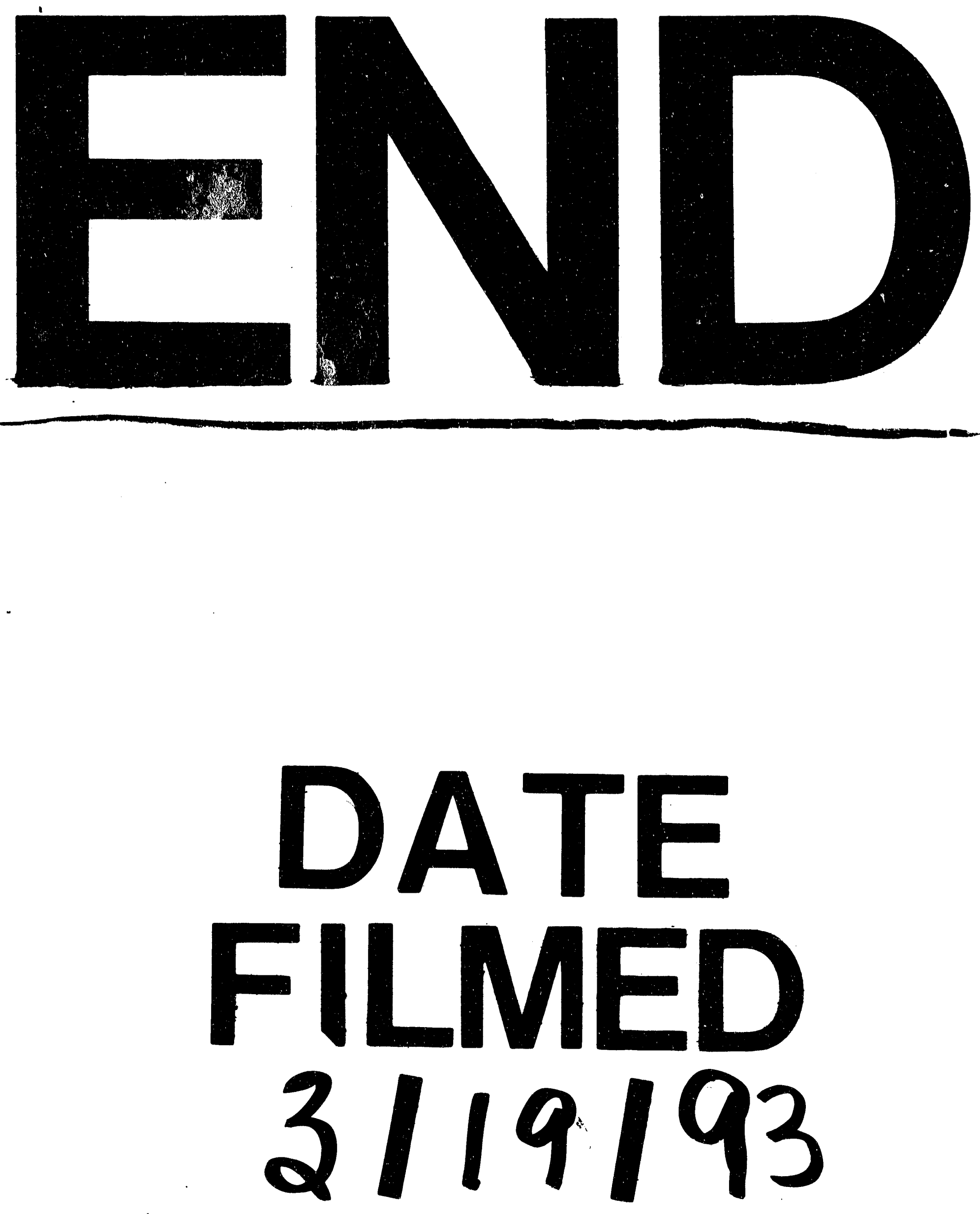
